\title{
O GÊNERO POETRY SLAM: REEXISTÊNCIA E CONSTRUÇÃO DA IDENTIDADE NEGRA COMO UM GRITO DAS VOZES DO SUL
}

\section{SLAM POETRY AS A GENRE: REEXISTENCE AND THE CONSTRUCTION OF BLACK IDENTITY AS A SCREAM FROM SOUTHERN VOICES}

\author{
Natália Barreto Felix \\ Centro Federal de Educação Tecnológica Celso Suckow da Fonseca, Rio de Janeiro, Rio de \\ Janeiro, Brasil \\ nbarretofelix@hotmail.com
}

Talita de Oliveira Centro Federal de Educação Tecnológica Celso Suckow da Fonseca, Rio de Janeiro, Rio de Janeiro, Brasil talita.oliveira.prof@gmail.com

Fabio Sampaio de Almeida Centro Federal de Educação Tecnológica Celso Suckow da Fonseca, Rio de Janeiro, Rio de Janeiro, Brasil fabioesp@hotmail.com

Maria Cristina Giorgi Centro Federal de Educação Tecnológica Celso Suckow da Fonseca, Rio de Janeiro, Rio de Janeiro, Brasil cristinagiorgi@gmail.com

Resumo: Partindo do poder de intervenção e invenção da linguagem (ROCHA, 2006, 2014), este trabalho objetiva compreender o poetry slam como gênero discursivo contemporâneo de reexistência (SOUZA, 2011) que ecoa vozes de sujeitos subalternizados sócio-historicamente - especialmente jovens negros das periferias - nossas vozes do sul. A proposta teóricometodológica foca-se na análise discursiva do poema-slam intitulado "Século XXI", do slammer carioca Weslley Jesus (WJ), disponível no YouTube. As análises apontam para posicionamentos de resistência aos discursos hegemônicos que legitimam a necropolíticas voltada para jovens negros das periferias brasileiras. Essas vozes apropriam-se da linguagem como instrumento estético-político-ideológico produzindo resistência ao racismo e a outras formas de opressão. Os resultados apontam para a importância de outros estudos sobre slam de modo a aprofundar as análises acerca desse gênero de reexistência, trazendo para o centro do debate vozes e demandas de sujeitos apartados da produção de conhecimento.

Palavras-chave: Slam; Gênero do Discurso; Reexistência; Identidade Negra; Vozes do Sul

Abstract: Considering the power of intervention and invention of language (ROCHA, 2006, 2014), this paper aims to understand poetry slam as a contemporary speech genre of reexistence (SOUZA, 2011) which echoes the voices of socio historically subordinated subjects - mainly peripheric young blacks - our southern voices. The theoretical-methodological proposal focuses 
on the discourse analysis of the slam-poem entitled "21st century", by Weslley Jesus (WJ) - a Rio de Janeiro slammer - available on YouTube. The analysis shows resistance positionings against hegemonic discourses that legitimate necropolitics destined to young blacks from the Brazilian peripheries. These voices make use of language as an aesthetic-political-ideological instrument that resists racism and other forms of oppression. The results point out the importance that other studies about slam poetry be carried out in order to further develop the analyses about this contemporary speech genre of reexistence, bringing the voices and demands of subjects who were taken away from knowledge production to the center of debate.

Keywords: Slam Poetry; Speech Genre; Reexistence; Black Identity; Southern Voices

\section{INTRODUÇÃO}

Parte da pesquisa contemporânea em Estudos da Linguagem tem se preocupado com o modo como nossos tempos vêm fazendo ecoar vozes e demandas sócio-historicamente tidas como periféricas e que, portanto, sequer eram entendidas como produtoras de conhecimento. Como consequência, à medida que epistemes não canônicas assumem centralidade em nossas pesquisas, redesenham-se visões de linguagem, emergem novos conceitos, tensionam-se metodologias tradicionais e incorporam-se agendas e perspectivas das vozes do sul (SZUNDY; TÍLIO; MELO, 2019). O "Sul", em consonância com Santos e Meneses (2009, p. 12), é pensado de forma metafórica "como um campo de desafios epistêmicos, que procuram reparar os danos e impactos historicamente causados pelo capitalismo na sua relação colonial com o mundo". Nesse sentido, outras narrativas e sujeitos passam a figurar na produção contemporânea de conhecimento, visibilizando saberes e práticas que reexistem (SOUZA, 2011) à tradição de pesquisa - em geral, fortemente ancorada em valores coloniais e eurocentrados.

No contexto do Brasil contemporâneo, negros, mulheres, jovens, favelados, sujeitos periféricos em geral - nossas vozes do sul - vêm buscando espaço como produtores de epistemes em diferentes campos: na literatura e nas artes, nas universidades, na política. De modo simultâneo, há um esforço permanente em valorizar espaços já comumente ocupados por esses sujeitos - como as ruas - como locais nos quais epistemes são construídas. O poetry slam corresponde a um exemplo de como as ruas da periferia se tornam cenário em que vozes negras e marginalizadas assumem protagonismo e reexistem pela potência da linguagem. Estamos diante de um novo gênero discursivo, nascido das emergências desses sujeitos que buscam ser vozes de resistência às opressões vividas, ao racismo e à exploração do capital.

A partir da compreensão de que a interação verbal é parte pulsante da atividade humana, e fazendo uma aposta no seu poder de intervenção e invenção (ROCHA, 2006, 2014), mais do que em seu caráter representacional, temos na língua(gem) um potente recurso de posicionamento para ser/estar no espaço, especialmente quando consideradas assimetrias sociais na distribuição das relações de poder, ou seja, quem é legitimado para dizer e que dizeres são legitimados para expressão de seus autores. A literatura e as artes, a despeito dos cânones consagrados pela elitizada e europeizada crítica especializada, desempenha(ra)m historicamente um papel de resistência às opressões e, quando se trata de literatura produzida por sujeitos subalternizados, essa é a regra.

Assim, o presente texto busca compreender o poetry slam (ou, simplesmente, slam) como um gênero discursivo contemporâneo de reexistência - à luz de Souza (2011) -, bem como pensar possíveis desdobramentos dessa prática discursiva na construção identitária dos poetas (slammers). Para tanto, iremos nos debruçar sobre o poema-slam "Século XXI", de Weslley Jesus (WJ), slammer carioca, para melhor compreendermos seus posicionamentos, seu contexto político-ideológico e as imbricações de seus discursos. 


\section{SLAM: UM GÊNERO DISCURSIVO (E SUBVERSIVO) DE REEXISTÊNCIA}

A palavra "slam" é oriunda de uma onomatopeia da língua inglesa empregada para indicar o som de uma batida de porta ou janela. Segundo Neves (2017), Marc Kelly Smith, trabalhador da construção civil e poeta, usou a palavra para nomear o Up-Town Poetry Slam, evento surgido em Chicago em 1984, passando a chamar de slams os campeonatos de performances poéticas que organizava nas periferias e nos quais os slammers eram avaliados pelo público. A iniciativa "viralizou", contagiando outras cidades dos EUA e, posteriormente, ganhando o mundo.

Para a exposição dos versos, a oralidade assume um lugar estelar na performance dos slammers. Nas rodas de slam, poetas usam traços performáticos, assemelhando-se a uma encenação teatral, para, ao tratarem de temáticas ligadas ao cotidiano dos jovens de periferia em especial, os negros -, atraírem a atenção dos ouvintes. A oralidade remete à ideia de memória coletiva, de saber compartilhado, nascido a partir da pluralidade de vozes e vivências. Ao mesmo tempo, o slam não descarta a modalidade escrita, mas busca na fala um modo de aproximar a plateia das reivindicações e angústias dos poetas. Com base em Bakhtin (2000) para quem os gêneros surgem e se modificam dentro de um momento histórico e a partir da necessidade de situações comunicativas específicas -, é possível olhar para o slam como um gênero emergente e de subversão marcado pelo hibridismo que desafia relações ou classificações simplistas entre oralidade e escrita no campo literário, uma vez que as rodas não constituem uma simples declamação do texto poético, mas uma performance oral, corporal, musical e interativa. Além disso, as rodas podem ser filmadas e transmitidas em mídias sociais, ampliando significativamente o público e redimensionando o tempo de circulação dos textos.

O gênero slam remete-nos à pluralização e ao dinamismo presentes nas realidades contemporâneas de seus enunciadores. A poesia do slam não evoca apenas questões sociais em sua temática, em seu conteúdo, mas também aponta para uma estrutura prosódica, melódica e gramatical construída no coletivo, a partir da interação.

É importante destacar, como característica das rodas de slam, certo grau de disputa não apenas territorial, mas sobretudo narrativa. Para além de o slam ser caracterizado por uma batalha poética diante de um júri e um público, o que está em jogo é a disputa pelo direito à palavra, à voz de jovens pretos periféricos historicamente silenciados. O slam é o momento em que "o lixo vai falar, e numa boa", como aponta Lélia Gonzales (1984). No contexto brasileiro, o slam parece surgir justamente como possibilidade do grito dessas vozes relegadas à margem. Pode-se, pois, dizer que, no ato da enunciação, o slam é marcado por uma defesa das vivências dos negros da periferia e da insistência na afirmação de que reexistem (SOUZA, 2011).

Uma das suas características quanto ao estilo verbal é a escolha pela manifestação coletiva da linguagem. Isso significa dizer que, por mais que tenhamos poemas criados por slammers de maneira individual, a partir de suas próprias vivências e particularidades, há também uma identificação e uma reação por parte do todo que recebe esses poemas, que é da ordem do múltiplo, do plural. As rodas de slam, ocorridas geralmente nas periferias e subúrbios da cidade, acontecem como resposta às privações por que passam as periferias no que diz respeito a, por exemplo, transporte de qualidade, acesso à cidade e, consequentemente, liberdade de ser. Assim, ao enunciar determinado poema e ter, em resposta, a concordância das rodas que participam daquele contexto, entendemos que o discurso propagado pelo slammer não pode ser visto apenas como enunciação individual, singular e manifestante de uma realidade pontual. Antes, diz respeito às vivências experienciadas por cada um deles, que expressam a concordância em coro com as temáticas trazidas para as rodas. Percebemos, assim, que a expressão de seus negros dizeres, bem como a movimentação poética de seus corpos negros, constantemente marginalizados, parecem remeter não apenas à dura realidade cotidiana 
enfrentada por eles, mas também, e principalmente, apontar para um grito comum, reexistente e de confronto social a partir da linguagem. Para tanto, podemos dizer que, por meio da consolidação de rodas como o slam, floresce um sentimento de pertencimento, de espelho diante da realidade do outro e de consequente reconhecimento.

Longe de propor uma ideia essencialista da construção identitária negra, entendemos que, pela negação e privação da ancestralidade e da cultura preta por parte de uma hegemonia branca e eurocentrada, há uma constante tentativa de reconstrução e resgate de memórias pelo movimento negro e por aqueles que procuram reacender ou ressignificar a narrativa que lhes foi violentamente sonegada. De acordo com Hall (2008, p. 109), as identidades são construções e têm muito mais a ver com questões como "quem nós podemos nos tornar", "como temos sido representados" e "como essa representação afeta como nós podemos representar a nós próprios" do que com "quem nós somos" ou "de onde nós viemos". Portanto, criar inteligibilidade sobre práticas discursivas como a do slam possibilita compreender como a construção de uma negritude que reexiste produz coletivamente modos epistêmicos, políticos e estéticos de intervenção social.

Sendo assim, na complexidade que caracteriza o gênero slam, interessa-nos compreender a produção de sentidos que determinadas escolhas linguístico-discursivas apontam na construção identitária de seus atores e da comunidade que recebe o discurso e dele se apodera. Entendemos, assim, que a construção de discursos e poéticas posicionadas, de caráter confrontante, como no slam, empoderam as identidades desses que a reiteram, fazendo ecoar o grito dessas "vozes do sul". Nesse sentido, buscamos analisar a linguagem enquanto intervenção (ROCHA, 2006) no social, e não apenas como algo estático e meramente representacional de uma realidade pré-existente dos sujeitos que por meio dela produzem enunciados.

\section{3 "A MINHA ENDOLA" É A LEITURA E O MEU FUZIL É O PAPO RETO": ANÁLISE DISCURSIVA DO POEMA-SLAM "SÉCULO XXI"}

Analisamos o poema-slam "Século XXI", do slammer Wesley Jesus (WJ), considerando a visibilidade do slam como um movimento artístico-cultural facilitador da manifestação de vozes marginalizadas e periféricas. Optamos por estabelecer um recorte analítico que privilegie o poema-slam - ou seja, a materialidade textual -, embora reconheçamos no slam um gênero que engloba outras propriedades, como a performance do slammer, a participação da plateia, a oralidade, o ritmo, a linguagem corporal, entre outros aspectos da roda poética.

O texto em análise (JESUS, 2017) foi retirado de uma roda de slam, divulgada pela Grito Filmes na plataforma de compartilhamento de vídeos YouTube. O vídeo, publicado em 4 de outubro de 2017, tem duração de 3 minutos e 46 segundos e, até o momento da escrita deste artigo (em 2 de julho de 2020), possuía 694.480 visualizações. Em seu poema-slam, WJ convida seus interlocutores imediatos (sentados ao seu redor) e os que assistem ao vídeo pelo YouTube a refletirem sobre a temática da raça, inerente à construção identitária de sujeitos periféricos, essas vozes do sul que, desde muito cedo, são constantemente lembradas do lugar a que pertencem, das privações de direitos a que estão submetidos, bem como do estigma social ao qual estão sujeitas rotineiramente. A seguir, o poema-slam de WJ na íntegra:

\footnotetext{
${ }^{1}$ Endolar: embrulhar, enrolar. Gíria comumente usada por usuários de drogas.
} 


\section{Século XXI - WJ}

1 Século XXI, onde tudo é comum

2 Policial que confundiu um negro com traficante e matou

3 Foda-se, era só mais um

4 Esse é o Brasil e esse aí é o meu povo

5 Mas eu aposto cem mil contigo que amanhã ele confunde de novo

6 Amanhã, depois e novamente

7 De dez traficantes que morre, uns nove é inocente

8 Mas como ser traficante e inocente ao mesmo tempo na vida?

9 É só dizer que é traficante e pronto, o mundo inteiro acredita

10 Até eu acredito pelo que foi dito pelo Supremo Veredicto

$11 \mathrm{E}$ ai de mim se não acreditar

12 Talvez não passe nem mais um dia vivo

13 Mas eu sou traficante também, hein, porra

14 Representante de Coelho Neto

15 A minha endola é a leitura e o meu fuzil é o papo reto

16 Século XXI, onde tudo é comum

17 Onde o rico escuta aplausos, e eu só escuto pá-tum

18 Onde o rico dorme feliz ao mar e suas ondas sucintas

19 Enquanto meu despertador é uma Glock com pente de 30

20 Mirada no alto, tem sangue no asfalto e uma bela senhora de salto

21 Mas novamente a PM confundiu um simples abraço com um grande assalto

$22 \mathrm{Eu}$ tenho uma pergunta dentro de mim que me segue como sombra

23 Mas eu vou abri-la com vocês, se vocês puderem, me respondam

24 Por que o rico pode e o pobre não pode?

25 Por que a gente usa Xperia

26 Enquanto eles usam iPod?

27 Ou por que o rico usa 50 ternos diferentes e eu to sempre com essa porra desse short?

28 Por que o rico é informante e o pobre é X9?

29 Por que o rico é portador de arma e o pobre é marginal com revólver?

30 Por que o rico recebe carinho e o pobre só recebe sacode?

31 Aí o rico me vê do outro lado dessa telinha,

32 A minha casa inteira na dele não dá a cozinha

33 Mas ele vai dizer que eu sou maluco e que eu não sei o que eu to falando

34 Mas o que ele teme em ver na TV é o meu verdadeiro cotidiano

35 Pessoas sendo mortas, metrô e trem lotado

36 Buzão quase sem porta, cadê o ar condicionado?

37 Isso é século XXI, porra!

$38 \mathrm{E}$ que a maldade não evolua

39 Se não daqui a pouco vão dizer nos jornais:

40 Pessoas pretas são proibidas na rua

41 Cabelo duro é pecado, beiço de mula é pecado

42 Branco é bonito ser gay e o preto é feio ser viado

43 Escravidão acabou?

44 Quem te enganou na resposta?

45 Escravidão acabou?

46 Quem te enganou na resposta?

47 Se acabou, por que que eu e meus irmãos sente a dor do chicote nas costas?

48 Aí família, dói, dói, o suor bate e arde

49 E eles podem me chamar de tudo, só não podem me chamar de covarde

50 Porque meu cabelo é duro

51 E o meu beiço é grande e eu me amarro

52 E me amarro pra caralho!

53 E cada rima constante vale bem mais que os seus carro

54 Porque esses carro no fumê só serve pra quem tá vivo

55 Mas o caráter e o saber, se eu morrer, eu levo comigo

$56 \mathrm{E}$ é por isso que eu prefiro: alface, azeite e vinagre

$57 \mathrm{E}$ depois de tanta verdade que eu falei

58 Se eu viver, vai ser milagre

(JESUS, 2017) 
Ao iniciar com o marcador temporal "Século XXI" (linha 1) - que também dá título ao poema-slam, o enunciador-poeta parece nos convidar à reflexão de que, apesar de estarmos na era da pós-modernidade, em pleno século XXI, o racismo e a banalidade expostos nas mortes de inocentes rotineiramente continua nos mostrando que as vidas pretas ainda são matáveis e que esse absurdo ainda é visto pela ordem do ordinário, do corriqueiro. Por meio do discurso do outro, o enunciador-poeta faz a denúncia do "Policial que confundiu um negro com traficante e matou/ Foda-se, era só mais um" (linhas 2 e 3 ). A voz do policial que justifica a morte se confunde com a do enunciador-poeta. Mais do que isso, o enunciador-poeta alerta para a legitimação dessas mortes por parte de uma elite que se isenta e, através de sua omissão, permite que esse ciclo de mortes e violência não seja interrompido.

É interessante pensar ainda que o uso do verbo "apostar", da locução adverbial "de novo", reforçadas pelos advérbios "amanhã", "depois" e "novamente" (linhas 5-6) remetem a uma noção de normalidade, cotidianidade, uma naturalização da mortalidade de corpos nas periferias ocasionada pelas forças de ordem, como também destaca a repetição desse evento sem que haja qualquer punição para seus agentes. O poema-slam dialoga, dessa forma, com discursos que alegam que corpos negros são "violentos", "sujos" e "destoantes" da norma desenhada pela própria hegemonia branca, o que justificaria uma truculência cada vez maior no trato com esses corpos, cada vez mais desumanizados em suas condições e animalizados por aqueles que detêm o poder, além de exemplificar a indiferença cíclica, fruto do racismo estrutural (ALMEIDA, 2018).

Destacamos a relevância da oposição entre o advérbio "só" e a expressão de sentido generalizante "o mundo inteiro" (linha 9) que ilumina alguns pressupostos (DUCROT, 1987) bastante naturalizados quando se trata de pessoas negras: "todo traficante é negro", "todo negro é traficante", que contribuem para reforçar o grau de desumanização de corpos tidos como malvados, danosos às "pessoas de bem", biologicamente marcados para serem perversos, como visto anteriormente. Há também uma oposição entre esses "traficantes" e "o mundo todo", legitimando o lugar de quem enuncia, de quem tem o poder de classificar esses indivíduos como "maléficos"; de quem determina e sela esses sujeitos, tratados como objetos, como vis e impiedosos. O homem branco é aquele reconhecido como sujeito que possui acesso ao espaço da não-favela, que tem seus direitos assegurados e, sobretudo, que tem garantido seu poder de intervenção no mundo por meio de uma palavra que é sempre legitimada, diga o que disser; aquele que tem a possibilidade de enunciar e ser escutado, de ser reprodutor de verdades hegemônicas, e, consequentemente, absolutas.

O texto de WJ, por meio das construções demonstrativas "esse" e "esse aí" e da designação "Brasil" (linha 4), aponta para um espaço-tempo discursivo que refrata a compreensão da realidade do país sob diferentes perspectivas. O discurso do slammer apresenta um panorama específico da realidade negra e periférica do país, reforçando que "Esse é o Brasil e esse aí é o meu povo" (linha 4): o povo preto, ainda que tal realidade não seja reconhecida por todos. É importante ressaltar que esse traço de territorialidade designa um determinado tipo de tratamento, bem como a garantia de que práticas violentas tenham liberação e aval social para ocorrerem em locais específicos da cidade: as favelas cariocas. Destacamos, ainda, que, por se tratar de um reflexo do racismo estrutural (ALMEIDA, 2018), a violência policial não é exclusiva do contexto carioca, mas sim comum à vivência de pretos e pobres em todo o país, já que é uma abordagem que se legitima e se assegura a partir da institucionalização de práticas racistas, que ratificam a exclusão e dominação de pessoas tomando como base a cor de sua pele.

Entre as linhas 22 a 30, evidencia-se a desigualdade constituída a partir do privilégio da classe média - majoritariamente branca - em detrimento da escassez e falta de oportunidades encontradas na periferia para a população negra. WJ recorre ao uso de paralelismo para contrastar essa visível discrepância que há entre o contexto do morador de periferia preto e o 
contexto do jovem branco de classe média. Além do emprego de paralelismo, por meio da exibição de ideias justapostas, há uma rítmica que pressupõe repetição de um movimento quase cíclico e sem fim. Como asseveram Souza e Albuquerque (2012, p. 112) acerca da interlocução entre identidade e construção discursiva:

\begin{abstract}
a compreensão que o sujeito tem de si se constitui através do olhar e da palavra do outro. Cada um de nós ocupa um lugar espaço-temporal determinado, e deste lugar único revelamos o nosso modo de ver o outro e o mundo físico que nos envolve. Nesta perspectiva de análise, a ênfase está no lugar ocupado pelo olhar e pela palavra na constituição do sentido que conferimos à nossa experiência de estar no mundo, sentido este atravessado por valores que fazem parte da cultura de uma dada época (SOUZA; ALBUQUERQUE, 2012, p. 112).
\end{abstract}

Partindo da compreensão bakhtiniana, de que o "eu" se constrói em relação ao outro e que a subjetividade é sempre intersubjetividade, as marcas linguísticas presentes no texto apontam para a construção de um sujeito coletivo, como se identifica pela marcação de plural em "Por que nós usamos Xperia enquanto eles usam Ipod?" (linhas 25 e 26). O poema-slam de WJ reforça a ideia de que as demandas trazidas por ele não são exclusivas à realidade dele enquanto homem preto, mas se manifesta em diversas outras realidades brasileiras como demanda coletiva. Como apontamos anteriormente, o slam faz emergir um coro que reverbera epistemes, estéticas, anseios e reivindicações de uma coletividade. A voz de WJ é, portanto, um amálgama de outras tantas vozes que buscam reexistir e empoderar suas identidades pelo potencial de intervenção da linguagem.

Ao longo do texto do poeta-slammer, identificamos marcas que apontam para discursos historicamente se alinhados com a inferiorização e aniquilamento do povo negro. Todavia, na voz de WJ, ao contrário, passam a fazer parte de uma crítica ao estigma ultrajante dado aos corpos negros. Na linha 41, o poeta, ao invés de renegar designações pejorativas, tais quais "beiço de mula" e "cabelo duro", apropria-se desses termos para se contrapor ao discurso racista que produz desqualificação da estética negra e animalização sobre corpos negros. Animalização que, de acordo com Santos (2002, p. 278), desde a Idade Média habita o imaginário europeu, que aproximava seres monstruosos às descrições de África e Ásia. Um mundo no qual o diabo era quase sempre pintado de preto e Satã chamado de Cavaleiro Negro ou de Grande Negro.

Entendemos que nossas análises reafirmam o poder de intervenção das vozes contrahegemônicas, como as vozes dos poemas-slams, que vêm se constituindo como espaços de insurgência preta. Os poetas-slammers-pretos-e-pretas denunciam, em versos, a opressão experimentada por eles em nosso país, deixando ecoar um fazer artístico para além dos muros das favelas; são gritos de indivíduos que se tornaram protagonistas de seus próprios dizeres, renegando assim a disciplinarização dos corpos (FOUCAULT, 2004) que lhes foi historicamente imposta. Como reitera Lima (2018, p. 27):

nós nos constituímos desde o princípio e no seu fim numa zona de exceção. A exceção nos marca e os seus efeitos modelam as práticas discursivas reatualizando os traços de colonialidade, colocando em suspensão o que realmente almejamos ou queremos dizer quando falamos em democracia, principalmente em contextos que se constituíram sob o mito da democracia racial (LIMA, 2018, p. 27).

Apontamos, assim, na análise do poema-slam, por meio da reapropriação e reconfiguração do discurso, uma proposta de repensarmos estratégias do racismo para o aniquilamento do povo preto, além de o discurso ser utilizado como ferramenta de resistência e reexistência (SOUZA, 2011) desses indivíduos, que são categoricamente subalternizados. 
Aprofundando o debate sobre a desvalorização desses corpos negros, que são tidos como matáveis, temos uma sociedade que legitima quem deve morrer e quem merece viver (MBEMBE, 2018). Com base na biopolítica de Foucault, o conceito de raça atravessa o pensamento e as práticas políticas do Ocidente, que, com base num eu hegemônico, desumanizam - com fins de dominação - o que acreditam ser povos estrangeiros. Passa-se do biopoder, do poder sobre a vida, à necropolítica, um poder de produção dos matáveis que, mais do que fazer viver, produz, delimita, marca aqueles que podem ser mortos, seguindo a lógica do racismo. Sendo assim, com base em Mbembe (2018), é possível compreender a necropolítica como um dispositivo para produção da população, que é o resultado do entrelaçamento de "soberania" e "raça". Uma soberania que não é movida pela desrazão, loucura ou instinto, mas pela mesma lógica civilizadora ocidental, na qual o estado de exceção é a regra.

Por fim, destacamos o potencial de transformação do slam, enquanto gênero discursivo contemporâneo que faz ecoar vozes historicamente estigmatizadas. O poema-slam "Século XXI", do slammer WJ, aponta a dimensão transformadora, interventiva e criativa da palavra e, ao mesmo tempo, pode ser compreendido com uma espécie de levante das nossas vozes do sul. Enquanto a necropolítica estatal segue vitimando corpos de jovens negros nas periferias das grandes cidades, a arma ("o fuzil" - linha 15) do poeta é a palavra ("o papo reto" - linha 15), ou seja, a intervenção pela via da linguagem. Assim, emerge o grito de sujeitos que resistem, reexistem e desafiam discursos hegemônicos, fazendo da endola a leitura (linha 15) e atribuindo alto valor ao poder de suas rimas (linha 53).

\section{CONSIDERAÇÕES FINAIS}

O presente texto teve como foco a análise linguístico-discursiva do gênero que denominamos poema-slam, do poeta carioca $\mathrm{WJ}$, na materialidade do gênero discursivo poetry slam. A linguagem aqui é tomada sob o ponto de vista da prática social e em sua relação com a produção de subjetividades por meio do discurso. Buscamos iluminar as vozes do sul, notadamente de jovens negros e periféricos, como forma de reexistência a uma estrutura social racista e necropolítica.

Sabemos que a linguagem é uma das práticas sociais de disputa de poder, que produz e ratifica desigualdades, corroborando ou rompendo com a manutenção do status quo. Portanto, apostamos no poder de intervenção de poesias marginais como as do slam, que constituem elementos de resistência ao racismo. A criação e propagação dessas poesias não seriam unicamente modos de expressão identitária, como também um movimento de apropriação e ressignificação da linguagem. Na medida em que esses indivíduos são massacrados por essa mesma linguagem - visto que, colocados à margem do debate acadêmico, têm sua fala cerceada e diminuída -, podemos dizer que há uma apropriação dessa linguagem como instrumento estético-político-ideológico. A partir da percepção de que é a branquidade ${ }^{2}$ valida o poder e legitimidade da construção de discursos socialmente hegemônicos, temos, no poema-slam, a necessidade da insurgência de vozes do sul, que se posicionem de maneira contrária à disseminação majoritária do discurso. Além disso, o levante dessas vozes nasce da urgência de subverter o drástico cenário.

Esperamos, com nosso artigo, abrir caminhos para que outros estudos sobre o slam, enquanto gênero discursivo contemporâneo de reexistência alinhado com as demandas de

\footnotetext{
${ }^{2}$ Optamos pelo termo branquidade, em lugar de branquitude, por estarmos nos referindo, como propõe Piza (2005), a "uma identidade branca negativa", produzida por práticas de pessoas brancas que se assumem como exemplo único de humanidade e pretendem a manutenção do seu privilégio social.
} 
grupos sócio-historicamente e racialmente subalternizados, sejam desenvolvidos no campo dos estudos da linguagem. Reconhecemos um esforço preliminar, mas não completo, em investigar elementos da ordem textual que apontam para a construção identitária coletiva dessas vozes do sul. Recomendamos que sejam empreendidas outras análises que considerem a performance dos slammers, o contexto interacional mais amplo em que os poemas-slam são oralmente construídos, bem como elementos prosódicos e rítmicos de tessitura poética, de modo a contribuir para novas teorizações e metodologias acerca dos estudos sobre gêneros discursivos na contemporaneidade.

\section{AGRADECIMENTOS}

O presente trabalho foi realizado com apoio da Coordenação de Aperfeiçoamento de Pessoal de Nível Superior - Brasil (CAPES) - Código de Financiamento 001. MCG agradece ao Conselho Nacional de Desenvolvimento Científico e Tecnológico $(\mathrm{CNPq})$ pela concessão da Bolsa de Produtividade em Pesquisa que possibilitou a realização desse estudo.

\section{REFERÊNCIAS}

ALMEIDA, S. L. O que é racismo estrutural? Belo Horizonte: Letramento, 2018.

BAKHTIN, M. Os gêneros do discurso. In: BAKHTIN, M. Estética da criação verbal. 3. ed. São Paulo: Martins Fontes, 2000, p. 277-326.

DUCROT, O. O dizer e o dito. Campinas: Pontes, 1987.

FOUCAULT, M. Vigiar e punir. Petrópolis: Vozes, 2004.

GONZALES, L. Racismo e sexismo na cultura brasileira. Revista Ciências Sociais Hoje, Anpoc, 1984, p. 223-244.

HALL, S. Quem precisa da identidade? In: SILVA, T. T. Identidade e diferença: a perspectiva dos estudos culturais. Petrópolis: Vozes, 2008, p.103-133.

JESUS, W. Século XXI. Slam resistência + Slam Grito Filmes wj. Rio de Janeiro: Grito Filmes, 2017. Disponível em: https://www.youtube.com/watch?v=68yppqmqZVE\&t=7s. Acesso em: 2 jul. 2020.

LIMA, F. Bio-necropolítica: diálogos entre Michel Foucault e Achille Mbembe. Arq. bras. psicol., v. 70, n. esp, p. 20-33, 2018. Disponível em:

http://pepsic.bvsalud.org/scielo.php?script=sci_arttext\&pid=S1809-

52672018000400003\&lng=pt\&nrm=iso. Acesso em: 17 mar. 2020.

MBEMBE, A. Necropolítica. São Paulo: n-1 edições, 2018.

NEVES, C. A. B. Slams - letramentos literários de reexistência ao/no mundo contemporâneo. Linha D’Água (Online), v. 30, n.2, p. 92-112, 2017. 
PIZA, E. Adolescência e racismo: uma breve reflexão. In: SIMPÓSIO INTERNACIONAL DO ADOLESCENTE, 1, 2005, São Paulo. Disponível em:

http://www.proceedings.scielo.br/scielo.php?script=sci_arttext\&pid=MSC0000000082005000 100022\&lng=en\&nrm=abn. Acesso em: 02 jul. 2020.

ROCHA, D. Representar e intervir: linguagem, prática discursiva e performatividade. Ling. (dis)curso, v. 14, n. 3, 2014, p. 619-632. Disponível em http://www.scielo.br/scielo.php?script=sci_arttext\&pid=S151876322014000300619\&lng=pt\&nrm=iso. Acesso em: 14 abr. 2020.

ROCHA, D. Representação e intervenção: produção de subjetividade na linguagem. Revista Gragoatá, v. 11, n. 21, 2006, p. 355-372. Disponível em: http://www.gragoata.uff.br/index.php/gragoata/article/view/317. Acesso em: 02 jul. 2020.

SANTOS, B. S.; MENESES, M. P. Epistemologias do Sul. Coimbra: Edições Almedina S. A., 2009.

SANTOS, G. A. Selvagens, Exóticos, Demoníacos. Idéias e Imagens sobre uma Gente de Cor Preta. Estudos Afro-Asiáticos, ano 24, n. 2, 2002, pp. 275-289. Disponível em: http://www.scielo.br/pdf/eaa/v24n2/a03v24n2.pdf . Acesso em 17 mar. 2020

SOUZA, A. L. S. Letramentos de reexistência: poesia, grafite, música dança: HIP-HOP. São Paulo: Parábola Editorial, 2011.

SOUZA, S. J.; ALBUQUERQUE, E. D. P. (2012) A pesquisa em ciências humanas: uma leitura bakhtiniana. Bakhtiniana, v. 7, n. 2, p. 109-122, 2011. Disponível em: http://www.scielo.br/scielo.php?pid=S2176$45732012000200008 \&$ script=sci_abstract\&tlng=pt. Acesso em 18 mar. 2020

SZUNDY, P. T. C.; TILIO, R.; MELO, G. C. V. (Orgs.). Inovações e desafios epistemológicos em linguística aplicada: perspectivas sul-americanas. Campinas: Pontes Editores, 2019.

Recebido em: 18 de março de 2020 Aceito em: 26 de junho de 2020 Publicado em Setembro de 2020 